TEXT AND THE CITY

ASIA-PACIFIC: CULTURE, POLITICS, AND SOCIETY

Editors: Rey Chow, H. D. Harootunian, and Masao Miyoshi 


\section{TEXT AND THE CITY}

ESSAYS ON JAPANESE MODERNITY

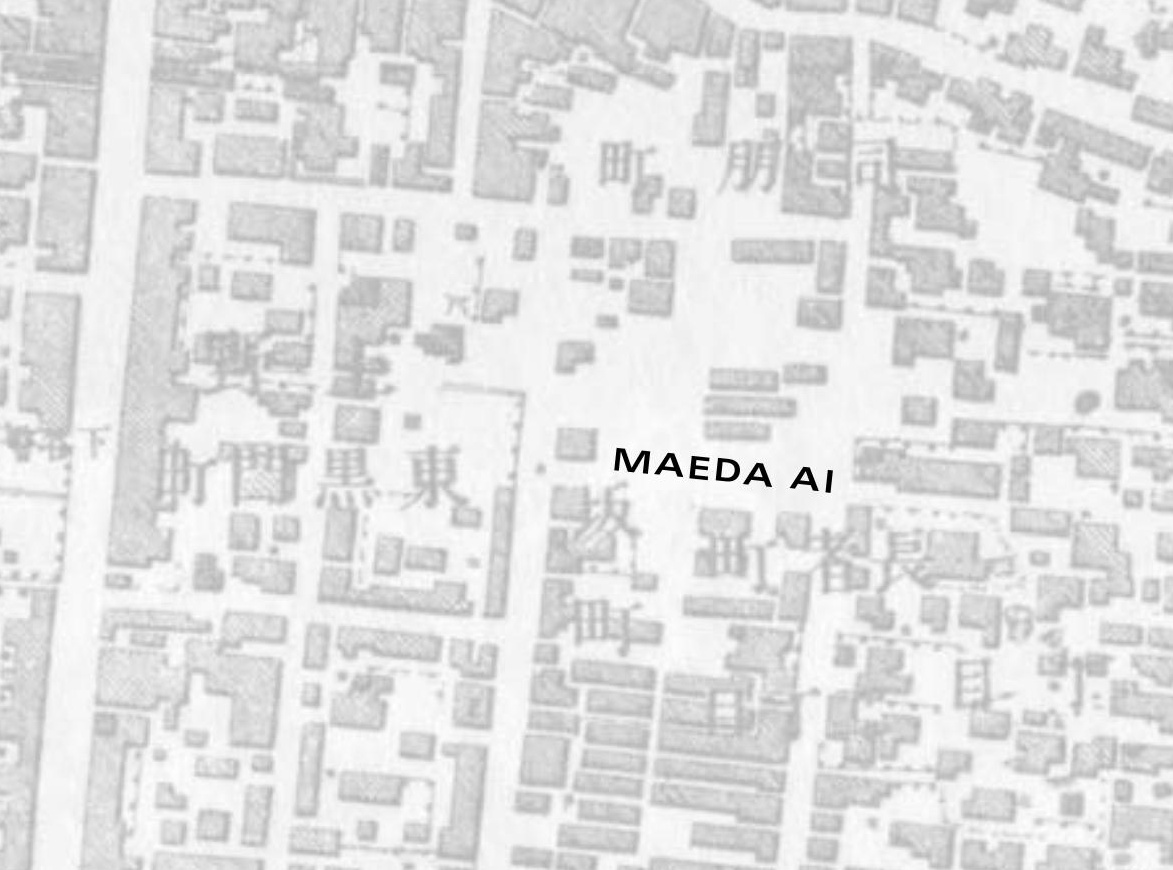

Edited and with an Introduction by JAMES A. FUJII
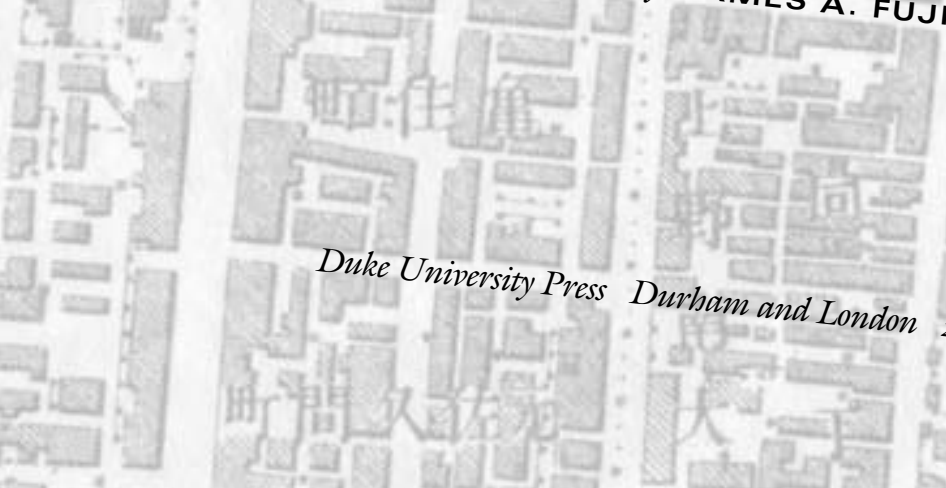

Duke University Press

Durbam and London

2004 
(C) 2004 DUKE UNIVERSITY PRESS. All rights reserved.

Printed in the United States of America on acid-free paper (a) Designed by Amy Ruth Buchanan. Typeset in Carter \& Cone Galliard by Tseng Information Systems, Inc. Library of Congress Catalogingin-Publication Data appear on the last printed page of this book. 